\title{
In vitro study of biocontrol potential of rhizospheric Pseudomonas aeruginosa against Fusarium oxysporum f. sp. cucumerinum
}

\author{
Md. Ariful Islam * (D), Zulkar Nain, Md. Khasrul Alam, Nilufa Akhter Banu and Md. Rezuanul Islam
}

\begin{abstract}
Fusarium wilt is an economically important disease of cucumber caused by the fungus Fusarium oxysporum f. sp. cucumerinum (Foc). It causes severe losses in the yield and quality of cucumber and is extremely difficult to control conventionally using chemical fungicides. Biological control offers an eco-friendly alternative to chemical pesticide for sustainable plant disease management. In this context, biocontrol activity of rhizosphere soil bacteria was investigated against FoC in vitro. Thirty-five rhizobacterial isolates were screened for antagonistic activity in dual culture, and isolate BA5 showed the highest antagonistic activity (58.33\% mycelial growth inhibition) against Foc. Maximum fungal biomass reduction (90.20\%) was found in King's B broth in shake flask culture. Cell-free culture filtrate and ethyl acetate crude extract inhibited mycelial growth of Foc by 56.66 and $25.0 \%$, respectively. Further, the selected isolate produced siderophores, volatile compound(s), hydrocyanic acid, and protease. Siderophores and volatile compound(s) were involved in the isolate-induced antagonism. In addition, the isolate exhibited several plant growth-promoting traits, including phosphate and zinc solubilization, ammonia production, organic acid production, and in vitro biofilm formation. Based on the morphological, physiological, biochemical characteristics, and phylogeny analysis, the isolate BA5 was identified as Pseudomonas aeruginosa, and the 165 rDNA sequence was submitted in the NCBI GenBank under the strain name RKA5. Because of the novel antifungal and plant growth promotion potentials, the strain can be used as a promising biocontrol agent against the fungal pathogen Foc.
\end{abstract}

Keywords: Biological control, Antagonistic activity, Fusarium, Cucumber, Pseudomonas aeruginosa, Fusarium oxysporum f. sp. cucumerinum

\section{Background}

Plant diseases account for $\sim 13 \%$ of the world's crop production lost, nearly equivalent to $\$ 220$ billion lost every year (Kandel et al. 2017). Among the crop pests, phytopathogenic fungi are the most common and cause a wide range of diseases to economically important plants (Mehnaz et al. 2013). Fusarium oxysporum, for example, is an important fungal pathogen known to cause vascular wilt diseases in more than 100 different species (Lopez-Berges et al. 2012). Fusarium oxysporum f. sp. cucumerinum $(F o c)$, a soil-borne pathogen, is the causal agent of vascular wilt disease in cucumber and causes significant yield loss (Al-Tuwaijri 2015). Cucumber
(Cucumis sativus L.) is one of the most important economical crops (Ahmed 2010) and commercially cultivated in Bangladesh throughout the year. Foc invades cucumber at any stage of development and colonizes the vascular vessel. The visible symptoms of the disease include necrotic lesions, followed by foliar yellowing, wilting, vascular tissue damage, and finally plant death (Ahmed 2010). It can grow along the xylem vessel in plant tissues and survive in soil as chlamydospores or saprophytes over a year (Yang et al. 2014), making it extremely difficult to control.

Use of synthetic fungicides is challenged due to the accumulation of these compounds in the ecosystem and the development of resistant fungal strains (Mehnaz

* Correspondence: ariful.btgeiu@gmail.com

Department of Biotechnology and Genetic Engineering, Faculty of Applied

Science and Technology, Islamic University, Kushtia 7003, Bangladesh 
et al. 2013). Interactions between antagonistic microorganisms and plant pathogens are widespread in nature and can be utilized to control or reduce fungal diseases of crop plants (Fridlender et al. 1993). Bacteria are vital components of soil (Ahemad and Kibret 2014), and over $95 \%$ of them exist in or near the plant roots (Ji et al. 2014). Rhizobacteria obtain their foods from root exudates and provide essential nutrients and protection to the plants; hence, it was rightfully stated that the rhizosphere is the "hotspot" of microbial interactions (Raaijmakers et al. 2009). The phenomenon of using beneficial soil microorganisms for plant disease management is known as biocontrol, and the microorganisms are known as biocontrol agents (Kandel et al. 2017). The antagonistic activities of bacterial biocontrol agents can be attributed to (i) synthesis of hydrolytic enzymes that can lyse fungal cell walls (such as chitinase, glucanase, protease, and lipases), (ii) competition for nutrients and niches, (iii) siderophores and antibiotic production, and (iv) induced systemic resistance (Beneduzi et al. 2012). In addition to their biocontrol activity, rhizobacteria also directly promote plant growth and health through "phytostimulatory" and "biofertilizing" traits (Raaijmakers et al. 2009).

A number of soil bacterial strains have been exploited for their plant growth promotion and biocontrol potentials, particularly the genera Bacillus (Lee et al. 2017), Pseudomonas (Priyanka et al. 2017), and Streptomyces (Lu et al. 2016). The genus Pseudomonas possesses superior biocontrol properties because of their adaptive metabolism and their ability to produce a range of antifungal compounds (Trivedi et al. 2008). Examples of antifungal and secondary metabolites produced by Pseudomonas spp. include phenazines ( $\mathrm{Hu}$ et al. 2014), 2,4-diacetylphoroglucinol (Zhang et al. 2016), pyoluteorin (Wu et al. 2011), pyrrolnitrin (Zhang et al. 2016), cyclic lipopeptides (Michelsen et al. 2015), siderophores (Sulochana et al. 2014), volatile compounds (Mannaa et al. 2017), hydrolytic enzymes (Solanki et al. 2014), and so on. Fluorescent pseudomonads, for example, Pseudomonas aeruginosa (Fatima and Anjum 2017), Pseudomonas putida (Yu and Lee 2015), and Pseudomonas fluorescens (Zhang et al. 2016), are well-known to protect plants from fungal infections.

The objectives of this study were to explore the biocontrol potentials of local rhizosphere soil bacteria against the cucumber wilt pathogen $F O C$ and to identify and characterize the prominent biocontrol bacterial isolate for antagonistic, enzymatic, and plant growth-promoting traits.

\section{Materials and methods}

\section{The fungal pathogen}

Fusarium oxysporum f. sp. cucumerinum (Foc), the causative agent of Fusarium wilt in cucumber, was obtained from Professor Dr. Md. Rezuanul Islam,
Department of Biotechnology and Genetic Engineering, Islamic University, Kushtia, Bangladesh. The fungal pathogen was grown on potato dextrose agar (PDA) plates incubated at $27 \pm 2{ }^{\circ} \mathrm{C}$ for 5 days. The fungal cultures were stored in PDA slants at $4{ }^{\circ} \mathrm{C}$ for further use.

\section{Isolation of rhizobacterial strains}

Six soil samples were collected from the rhizosphere of five different crop/vegetable plants, namely mustard (Brassica campestris), pea (Pisum sativum), bathua (Chenopodium album), lentil (Lens culinaris), and radish (Raphanus sativus), grown in agricultural fields located near the Islamic University, Kushtia, Bangladesh. Soil bacteria were isolated from the samples by serial dilution technique. Briefly, $5 \mathrm{~g}$ of soil sample was suspended in $45 \mathrm{ml}$ of sterile distilled water and shaken at $120 \mathrm{rpm}$ on a rotary shaker for $10 \mathrm{~min}$. The soil mixture was diluted 1:10 ratio with distilled water up to $10^{-7}$. An aliquot of $100 \mu \mathrm{l}$ from $10^{-4}$ to $10^{-7}$ dilutions was distributed in tryptone soya agar (TSA) plates and gently spread with a sterile glass rod spreader. The plates were incubated at $30 \pm 2{ }^{\circ} \mathrm{C}$ for 2 days, after which morphologically distinct colonies were subcultured onto the same medium in another plate to isolate single colonies. The purified bacterial isolates were maintained in Eppendorf tubes in tryptone soya broth (TSB) containing $20 \%$ glycerol at $80{ }^{\circ} \mathrm{C}$ (Han et al. 2015).

\section{In vitro mass screening for antagonistic activity}

In vitro screening for antagonistic activity was performed by dual culture technique on PDA plates. Briefly, PDA medium was prepared and poured $(20 \mathrm{ml})$ in sterile Petri dishes. A 5-mm agar disc of an actively growing culture of $F o c$ was placed in the center of each plate. Each isolate was streaked $3 \mathrm{~cm}$ away from the agar disc towards the edge of the Petri dish. In the control plate, no bacterial isolate was inoculated. Plates were parafilmed and incubated at $27 \pm 2{ }^{\circ} \mathrm{C}$ for 5 days until the fungal mycelia reached the edge in the control plates. Mycelial growth inhibition towards the direction of the bacterial isolate was indicative of antagonistic activity. Percentage (\%) of radial mycelial growth inhibition was calculated according to Ji et al. (2013).

\section{Quantitative evaluation of antagonism of the selected isolate} One milliliter $\left(A_{600}=0.2\right)$ culture broth of the selected isolate, i.e., isolate BA5, and a $5-\mathrm{mm}$ disc of an actively growing culture of $F o c$ were inoculated in $50 \mathrm{ml}$ broth medium in $250 \mathrm{ml}$ conical flasks and incubated at $27 \pm 2{ }^{\circ} \mathrm{C}$ for $48 \mathrm{~h}$ on a rotary shaker. Five different media (potato dextrose, King's B, tryptone soya, nutrient, and tryptone yeast extract broth) were used. Broth inoculated only with Foc served as 
control. Reduction in fungal biomass in co-culture compared to control was determined (Trivedi et al. 2008).

\section{Antagonism due to volatile compound(s)}

A bacterial lawn of isolate BA5 was prepared on TSA plate, and after incubation for $24 \mathrm{~h}$, the lid was replaced by a plate containing an agar disc ( $7 \mathrm{~mm}$ diameter) of Foc grown on PDA. The two plates were sealed together with parafilm. Control plates were prepared similarly without the bacterial isolate in the bottom plate. Such sealed sets of Petri dishes were incubated at $27 \pm 2{ }^{\circ} \mathrm{C}$, and the observations were recorded at intervals of 24 for $72 \mathrm{~h}$. The mycelial growth inhibition (\%) of the fungus was determined (Trivedi et al. 2008).

\section{Evaluation of the effect of cell-free culture filtrate} Isolate BA5 was grown on nutrient broth medium in 250 -ml conical flask at $30 \pm 2{ }^{\circ} \mathrm{C}$ on a rotatory shaker at $100 \mathrm{rpm}$. Culture broth after 24 and $48 \mathrm{~h}$ of incubation was centrifuged at $10,000 \mathrm{rpm}$ at $4{ }^{\circ} \mathrm{C}$ for $10 \mathrm{~min}$, and cell-free culture filtrate (CFCF) was obtained by passing the supernatant through $0.22 \mu \mathrm{m}$ pore size syringe filter. PDA plates were prepared, and a mycelial disc of an actively growing culture of $F o c$ was placed in the center of each plate. Two wells $(5 \mathrm{~mm})$ were made with sterile cork borer $3 \mathrm{~cm}$ away from the center and aliquoted with $100 \mu \mathrm{l}$ of CFCF. Plate in which wells were aliquoted only with nutrient broth served as control. Plates were incubated at $27 \pm 2{ }^{\circ} \mathrm{C}$ for 5 days. Mycelial growth inhibition (\%) was measured as described above.

\section{Evaluation of organic solvent-aided crude extract activity}

The effect of organic solvent-aided crude extract in fungal growth inhibition was carried out as described previously (Islam et al. 2012). The crude antifungal substance was recovered from the culture broth of isolate BA5 by solvent extraction (ethyl acetate and chloroform). The extracts were dried, weighed, dissolved in methanol, and stored at $4{ }^{\circ} \mathrm{C}$. Antifungal activity of the resulting crude compound(s) was evaluated in agar well diffusion assay.

\section{Characterization of antagonistic and enzymatic properties} Hydrocyanic acid (HCN) production was tested as described previously (Trivedi et al. 2008). Siderophore(s) and their chemical nature were examined as described in Yeole et al. (2001). Involvement of siderophore in antifungal activity was evaluated according to the method of Kumar et al. (2002). Cyclic lipopeptide (CLP) surfactant production was assessed according to De Bruijn and Raaijmakers (2009). Proteolytic activity was screened in nutrient agar plates supplemented with 3\% skim milk powder (Han et al. 2015). Assay for cellulase production was done according to Kasana et al. (2008), and extracellular amylase production was screened on starch agar plates (Deb et al. 2013).

\section{Characterization of plant growth promotion traits of the selected isolate}

Phosphate solubilizing activity was qualitatively detected in Pikovskaya's agar (PKV) medium (Kumar et al. 2005). The solubilizing efficiency was calculated using the following formula: solubilizing efficiency (\% S.E.) $=(Z-C) /$ $C \times 100 ; Z=$ solubilization zone $(\mathrm{mm})$ and $C=$ colony diameter $(\mathrm{mm})$. The solubilizing zone around the colony was calculated by subtracting colony size from the total size. Zinc solubilizing activity was carried out in a modified PKV agar medium (Bapiri et al. 2012). Organic acid production was assessed using PKV agar medium with bromothymol blue indicator (Kumar et al. 2012). Nitrogenase activity was detected in Norris glucose nitrogen-free medium. Indoe-3-acetic acid (IAA) production was determined by the method reported by Bric et al. (1991). Isolate BA5 was grown on LB broth supplemented with $5 \mathrm{mM}$ L-tryptophan and incubated at $30 \pm 2{ }^{\circ} \mathrm{C}$ for $48 \mathrm{~h}$. The culture broth was centrifuged at 10,000 rpm for $15 \mathrm{~min}$ at $4{ }^{\circ} \mathrm{C}$, and the supernatant was collected. The supernatant $(2 \mathrm{ml})$ was mixed with two drops of O-phosphoric acid and $4 \mathrm{ml}$ of Salkowski reagent $(50 \mathrm{ml}, 35 \%$ of perchloric acid, $1 \mathrm{ml} 0.5 \mathrm{M} \mathrm{FeCl}_{3}$ solution) (Gordon and Weber 1951). The appearance of a pink color in the supernatant confirmed the production of IAA. Assay for ammonia production was performed as discussed in Trivedi et al. (2008). In vitro biofilm formation was carried out as described by Zhou et al. (2012).

\section{Identification of the selected isolate}

Morphological, physiological, and biochemical characterization Morphological and biochemical tests were performed as described in Benson's Microbiological Applications Lab Manual (Benson 2002).

The ability of isolate BA5 to grow at different temperature was carried out by inoculating the isolate on TSA (pH 7.0) medium and incubating the plates at varying temperature, viz. 4, 25, 37, 42, and $50{ }^{\circ} \mathrm{C}$. Growth was evaluated either as positive $(+)$ or negative $(-)$. The capability of the isolate to tolerate different osmotic pressure was performed by culturing in different concentration of sodium chloride. Nutrient broth medium ( $\mathrm{pH}$ 7.0) was prepared (in 50-ml conical flasks) supplemented with 0.5 , $1,3,5,7$, and $9 \% \mathrm{NaCl}(w / v)$ and inoculated with the isolate. The presence of growth was evaluated by observing turbidity after an incubation period of 24 and $48 \mathrm{~h}$ at $30 \pm$ $2{ }^{\circ} \mathrm{C}$. Growth in different $\mathrm{pH}$ was observed by inoculating the isolate in nutrient broth medium of varying $\mathrm{pH}$ (4.0, $5.0,7.0,9.0,10.0$, and 11.0 ) at $30 \pm 2{ }^{\circ} \mathrm{C}$ for $24-48 \mathrm{~h}$. The $\mathrm{pH}$ of the broth was adjusted with $1 \mathrm{~N} \mathrm{NaOH} / \mathrm{HCl}$ with the help of a $\mathrm{pH}$ meter. 
The ability of isolate BA5 to utilize a range of organic compounds as the sole source of carbon and energy was determined in modified Koser citrate medium (Koser 1923). In the basal medium, di-ammonium hydrogen orthophosphate was used in place of sodium-ammonium phosphate, and various organic compounds were added in place of sodium citrate. In addition, sodium chloride was added at $5 \mathrm{~g} / \mathrm{l}$ concentration. The basal medium, without the carbon sources, was autoclaved at $121{ }^{\circ} \mathrm{C}$, 15 psi for 15 min. Each of the carbon sources was dissolved in sterile distilled water, filter sterilized, and added to the basal medium at $0.3 \%$ final concentrations, except phenol, which was added at $0.025 \%$ (Stanier et al. 1966). Three test tubes with the same carbon source and one tube without the carbon source (control) were inoculated with isolate BA5 and incubated at $30 \pm 2{ }^{\circ} \mathrm{C}$. The inoculated test tubes were scored after 24,48 , and $72 \mathrm{~h}$. The growth was recorded as "+" (positive, growth) or "-" (negative, no growth).

\section{Molecular identification of isolate BA5 \\ Extraction of genomic DNA, PCR, and sequencing}

Genomic DNA was extracted by phenol: chloroform:iso-amyl alcohol method following the protocol described in He (2011). PCR was performed from the genomic DNA by using $16 \mathrm{~S}$ rDNA bacterial universal primer set of 27F (5-AGA GTT TGA TCC TGG CTC AG-3) and 1492R (5-GGC TAC CTT GTT ACG ACT T-3). The purified PCR product was sequenced in 4-capillary $\mathrm{ABI}$ 3130 genetic analyzer from Applied Biosystems.

\section{Sequence analysis and phylogeny interpretation}

The obtained sequence was compared for similarity with sequences present in the gene database bank by using the BLASTn program in the GenBank of NCBI (National Center for Biotechnology Information; http:// blast.ncbi.nlm.nih.gov/Blast.cgi). The higher similarity sequences of $16 \mathrm{~S}$ rRNA gene of type strains were retrieved and aligned with the $16 \mathrm{~S}$ rRNA gene sequence of isolate BA5 in ClustalW program and subjected to a phylogenetic tree construction in MEGA7 (Kumar et al. 2016) with 1000 bootstrap replications, and evolutionary history was inferred using the neighbor-joining method (Saitou and Nei 1987).

\section{Statistical analysis}

All experiments were conducted in triplicate, and data were presented as means \pm standard deviations (mean $\pm \mathrm{SD}$ ) where appropriate. Data were statistically analyzed by one-way ANOVA and two-tailed $t$ tests using Microsoft Excel $^{\text {Tn }}$ 2013. Intergroup differences were considered to be statistically significant when $P \leq 0.05$ and highly significant when $P \leq 0.001$. Graphs were prepared in scientific 2D graphing software, GraphPad Prism.

\section{Results and discussion}

\section{Mass screening for antagonistic activity}

A total of 35 bacterial isolates were obtained from rhizosphere soils of five different crop/vegetable plants by serial dilution technique. In vitro screening for antagonistic activity was carried out in dual culture on PDA plates. Among the 35 isolates, five isolates showed different degrees of mycelial growth inhibition of Foc (Fig. 1a). Isolate BA5 (isolated from rhizosphere soil of bathua, Chenopodium album), was the most promising antagonist (58.33\% mycelial inhibition, significant at $P \leq 0.001$ ) (Fig. 1a, and b) and selected for further investigations.

In vitro dual culture test is one of the key tests used for preliminary screening of biological control agents. Antagonistic effects are usually confirmed by the formation of inhibition zones between the bacteria isolates and the fungal isolates (Ji et al. 2014) or by measuring the percent of radial mycelial growth inhibition towards the bacterial isolates (Lee et al. 2017).

Quantitative evaluation of antagonism in different media Antagonistic activity of the prominent isolate BA5 was also screened in broth-based dual culture. Fungal biomass was considerably reduced in broth media inoculated with isolate BA5 compared to the fungus only (Fig. 1c). Significant reduction of Foc biomass was found in King's B broth (90.20\%), nutrient broth $(86.38 \%)$, and potato dextrose broth $(75.92 \%)$ compared to the respective fungus-only controls. According to Trivedi et al. (2008), in vitro broth-based dual cultures offer a better method for evaluation of the antagonistic efficiency of the biocontrol agents as the liquid medium may provide a better environment to allow the antagonistic activities from all possible interacting sites.

\section{Antagonism due to volatile compound(s)}

Volatile compounds such as ammonia and hydrogen cyanide are produced by a number of rhizobacteria and are reported to play an important role in biocontrol. Isolate BA5 produced antifungal volatile compound(s) (VOCs), as evident from the growth inhibition of Foc in sealed Petri dishes. Radial mycelial growth was significantly inhibited (31.11\%) compared to control (Table 1, Fig. 1d). In addition, aerial mycelial growth was also reduced due to the effect of volatile metabolites. Raza et al. (2016) demonstrated the role of VOCs produced by P. fluorescens WR-1 in biocontrol activities. Kandel et al. (2017) and Lee et al. (2017) also reported VOCs mediated antifungal activities recently.

\section{Antifungal activity of cell-free culture filtrate}

Cell-free culture filtrate (CFCF) exhibited significant antifungal activity against Foc. Maximum mycelial growth inhibition (54.16\%) was found with CFCF from 48-h-old 


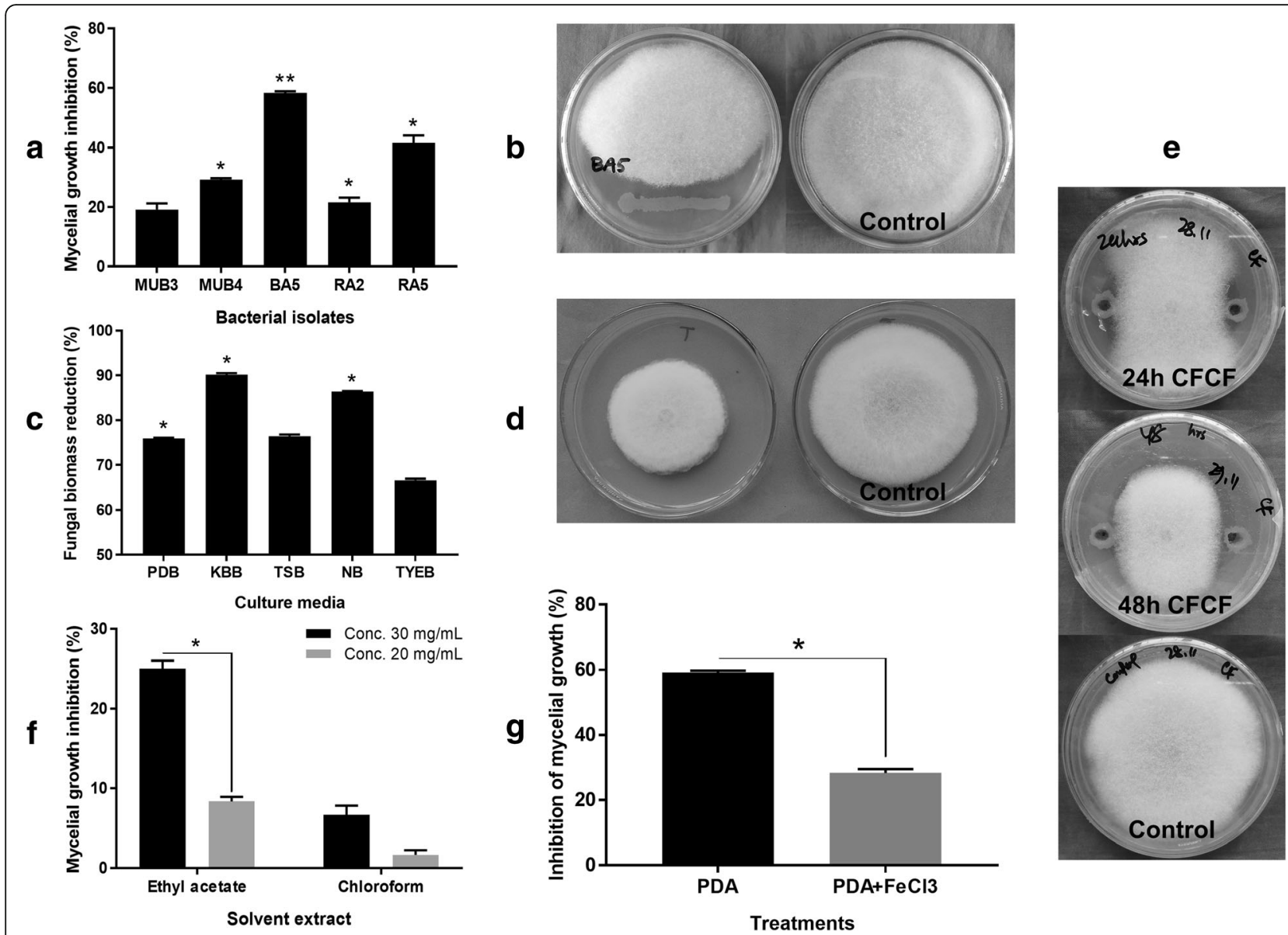

Fig. 1 Antagonism of isolate BA5 against Fusarium oxysporum f. sp. cucumerinum (Foc). a Antagonistic activity of soil bacterial isolates against Foc on potato dextrose agar (PDA), $\mathbf{b}$ antagonistic activity of isolate BA5 against Foc in dual culture on PDA after 5 days of culture at $27 \pm 2{ }^{\circ} \mathrm{C}$, c biomass reduction of Foc in broth-based dual culture with isolate BA5 in different media, $\mathbf{d}$ mycelial growth inhibition of Foc due to production of volatile compound(s), e Foc mycelial growth inhibition by cell-free culture filtrate from BA5 in dual culture on PDA, $\mathbf{f}$ antifungal activity of the solvent-aided crude substance of isolate BA5 against Foc, and $\mathbf{g}$ siderophore-mediated antagonism of isolate BA5 against Foc. Vertical bars represent standard deviations. The number of asterisks indicates the level of significance: a single asterisk $\left(^{*}\right)$ as significant $(P \leq 0.05)$ and double asterisks $\left(^{* *}\right)$ as highly significant $(P \leq 0.001)$

culture broth followed by (45.83\%) with CFCF from 24-h-old culture broth (Table 1, Fig. 1e). Li et al. (2011) showed that CFCF of Streptomyces globisporus JK-1 inhibited mycelial growth of Magnaporthe oryzae.

\section{Antifungal activity of crude bioactive compound(s)}

The resulting crude extracts of both ethyl acetate and chloroform solvents were brownish in color, sticky, and readily dissolved in methanol. Both solvent extracts showed mycelial growth inhibition of $F o c$ in a concentration-dependent manner (Fig. 1f). However, $30 \mathrm{mg} / \mathrm{ml}$ ethyl acetate extract showed significant (25.0\%) mycelial growth inhibition compared to $20 \mathrm{mg} / \mathrm{ml}$ concentration. Upon further incubation, fungal mycelia became powdery and brittle. Chloroform extract crude substance showed insignificant mycelial inhibition of Foc. Evaluation of crude compound(s) for bioactivity is the prerequisite for further purification and identification of the antifungal metabolites. It is often regarded as one important preliminary screening for structural and functional characterization of bioactive compound(s). Kumar et al. (2005) purified a broad-spectrum antifungal compound from the ethyl acetate crude extract of $P$. aeruginosa PUPa3.

\section{Antagonistic and enzymatic characteristics}

Antagonistic and enzymatic properties of isolate BA5 were examined by various tests (Table 1 ). A remarkable change in the color of filter paper from yellow to light brown suggested the moderate $\mathrm{HCN}$ production in isolate BA5 (Fig. 2a). HCN is a broad-spectrum antimicrobial compound involved in biological control of root diseases by many plant-associated fluorescent pseudomonads (Ramette et al. 2003). Dharni et al. (2012) also reported a $P$. aeruginosa SD12 with the ability to produce $\mathrm{HCN}$. 
Table 1 Antifungal, antagonistic, enzymatic, and plant growth promoting activity of isolate BA5

\begin{tabular}{|c|c|}
\hline Test & Result \\
\hline Antifungal activity & $\%$ mycelial growth inhibition $( \pm S D)^{a}$ \\
\hline Volatile compound(s) ${ }^{\mathrm{b}}$ & $31.11 \pm 0.57^{* *}$ \\
\hline $24 \mathrm{~h} \mathrm{CFCF}^{\mathrm{C}}$ & $45.83 \pm 2.08^{*}$ \\
\hline $48 \mathrm{~h} \mathrm{CFCF}^{\mathrm{d}}$ & $54.16 \pm 0.57^{* *}$ \\
\hline Antagonistic properties & Activity \\
\hline HCN production ${ }^{\mathrm{e}}$ & + \\
\hline CLP surfactant production ${ }^{f}$ & - \\
\hline Siderophore production & + \\
\hline \multicolumn{2}{|l|}{ Enzymatic properties } \\
\hline Protease & + \\
\hline Cellulase & - \\
\hline Amylase & - \\
\hline \multicolumn{2}{|c|}{ Plant growth promotion properties } \\
\hline Phosphate solubilizationg & + \\
\hline Zinc solubilization ${ }^{\mathrm{h}}$ & + \\
\hline Organic acid production & + \\
\hline Nitrogenase activity & - \\
\hline IAA production & - \\
\hline Ammonia production & + \\
\hline In vitro biofilm formation & + \\
\hline
\end{tabular}

aEffect of volatile compound(s) and cell-free culture filtrate (CFCF) from isolate BA5 on mycelial growth inhibition of Foc. ${ }^{\mathrm{b}}$ Mycelial growth was measured after $72 \mathrm{~h}$ of culture in sealed Petri dish. ${ }^{c \& d}$ CFCF obtained from 24- and 48-h-old culture broth of isolate BA5, respectively. ${ }^{*}$ and ${ }^{* *}$ significant at $P \leq 0.05$ and $P \leq 0.001$ level, respectively. ${ }^{\mathrm{e}} H C N$ hydrocyanic acid. ${ }^{\mathrm{f}} \mathrm{C} L P$ cyclic lipopeptide. The test medium was supplemented with insoluble ${ }^{\mathrm{g}}$ tri-calcium phosphate and ${ }^{\mathrm{h}} \mathrm{zin}$. oxide, respectively. " + " indicates positive activity and " - " indicates no activity

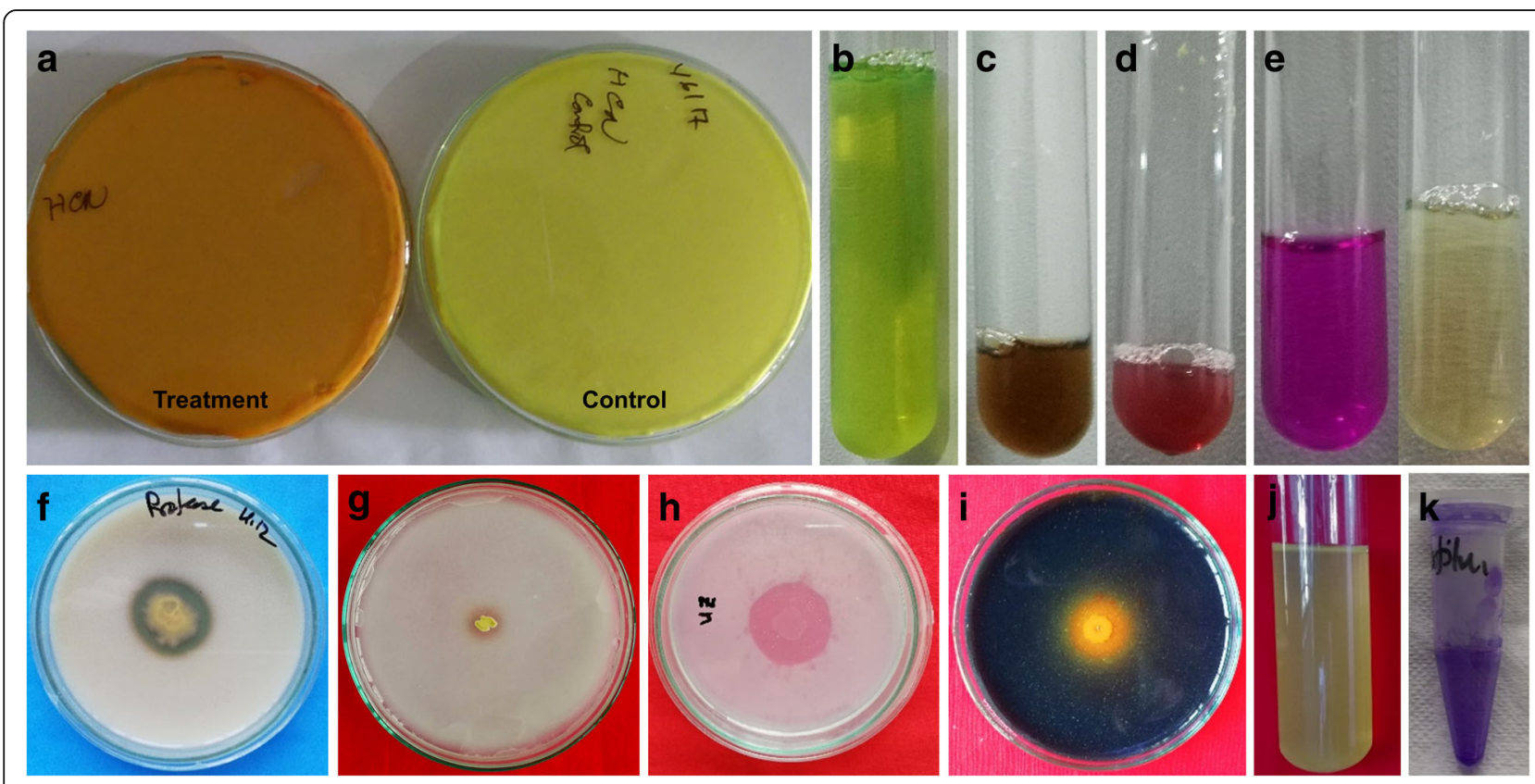

Fig. 2 Antagonistic, enzymatic, and plant growth-promoting potentials of isolate BA5. a HCN production, b siderophores obtained as cell-free culture filtrate, $\mathbf{c ~ F e C l} 3$ test, $\mathbf{d}$ tetrazolium salt test, e Vogel's chemical test, $\mathbf{f}$ protease activity, $\mathbf{g}$ phosphate solubilizing activity, $\mathbf{h}$ zinc solubilizing activity, $\mathbf{i}$ organic acid production, $\mathbf{j}$ ammonia production, and $\mathbf{k}$ biofilm formation in plastic Eppendorf tube 
Siderophore production and chemical nature of siderophore were confirmed by chemical and spectrophotometric assays. The CFCF obtained by centrifuging the 72-h-old culture broth was light green to yellowish green (Fig. 2b). Formation of dark orange to light brown color of the CFCF after addition of $2 \%$ aqueous $\mathrm{FeCl}_{3}$ solution was confirmative for siderophore production (Fig. 2c). Isolate BA5 produced two types of siderophores. In tetrazolium salt test, the appearance of a red color indicated the production of hydroxamate-type siderophore (Fig. 2d), and the absorption maximum of the iron-siderophore complex at $450 \mathrm{~nm}$ in UV-Vis spectrophotometer further confirmed the hydroxamate nature of the siderophore. Carboxylate-type siderophore was confirmed in Vogel's chemical test. Addition of the CFCF to the alkaline phenolphthalein solution made the light pink color of the solution disappeared instantly (Fig. 2e); however, the carboxylate nature of siderophore was not confirmed in the spectrophotometric assay.

The role of siderophores in biocontrol has extensively been studied previously (Solans et al. 2016). Siderophores can inhibit the growth of soilborne fungi by reducing the amount of ferric ions available to rhizosphere microflora. It has also been stated that colonization of the rhizosphere, production of antibiotics, and their antagonistic activity of $P$. aeruginosa are presumably due to the production of the siderophores (Sulochana et al. 2014). Hydroxamate siderophores are common among the bacterial community (Yeole et al. 2001 and Dharni et al. 2012); however, carboxylate siderophores have not been reported very often. Tian et al. (2009) reported that Pseudomonas sp. G-229-21 could produce high-affinity carboxylate-type siderophores under low iron conditions.

Siderophores are not produced in the presence of iron (Kumar et al. 2002). Mycelial growth inhibition rate was significantly $(P \leq 0.05)$ reduced $(28.33 \%)$ in $\mathrm{FeCl}_{3}(100 \mu \mathrm{g} / \mathrm{ml})$ supplemented plates compared to in no $\mathrm{FeCl}_{3}$ supplemented PDA plates (59.16\%) (Fig. 1g). This is suggestive that siderophore was one of the key antifungal metabolites in the isolate BA5-induced antagonism.

Petri dish-based qualitative assays revealed that isolate BA5 produced protease but not amylase and cellulase. A clear zone on skim milk agar was evident for strong protease activity, measuring $7 \mathrm{~mm}$ halo zone after 3 days of culture at $30 \pm 2{ }^{\circ} \mathrm{C}$ (Fig. 2f). Proteolytic activity has also been reported in Pseudomonas spp. in several studies (Dharni et al. 2012 and Zhou et al. 2012).

\section{Plant growth promotion characteristics}

Several plant growth-promoting properties were evaluated in vitro (Table 1). A clear zone surrounding the BA5 colony on PKV agar medium (Fig. 2g) indicated the phosphate solubilizing activity of the isolate. The diameter of the halo zone was $3 \mathrm{~mm}$, and the phosphate solubilizing efficiency (S.E.) was $62.5 \%$. Zinc solubilizing activity was indicated by the formation of a clear halo zone (8 mm; S.E. 47.05\%) surrounding the colony on modified PKV agar medium supplemented with insoluble $\mathrm{ZnO}$ (Fig. 2h). Organic acid production was evident by the change of the color of bromothymol blue indicator from blue to orange-yellow (Fig. 2i) due to a decrease in the $\mathrm{pH}$ of the growth medium. No growth on Norris nitrogen-free glucose medium suggested the absence of nitrogenase activity in the isolate BA5. The presence of a light yellow color after the addition of Nessler's reagent to peptone water culture of isolate BA5 indicated the production of ammonia (Fig. 2j). The absence of pink/red color upon addition of Salkowski reagent to the culture supernatant indicated no IAA production by the isolate BA5. The trace of crystal violet in the Eppendorf tube (Fig. 2k) was indicative of in vitro biofilm formation by isolate BA5, suggesting its potential colonization ability in plant roots.

Phosphorus is one of the key mineral nutrients required for the growth and yield of agriculturally important crops. Phosphate solubilizing bacteria solubilize mineral phosphate in nature by secreting organic acids and/or enzymes (Paul and Sinha 2017). Change in the color of the bromothymol indicator from blue to yellow-orange was suggestive that phosphate solubilization by isolate BA5 was probably due to the production of organic acid(s). Phosphate solubilizing Pseudomonas sp. was previously reported from rhizoplane of rice in Bangladesh (Islam et al. 2007). Zinc solubilization in $P$. aeruginosa and $P$. fluorescens has been reported by Bapiri et al. (2012). Several workers have described biofilm formation in plastic Eppendorf tubes (Zhou et al. 2012).

\section{Identification of the selected isolate}

The morphological, biochemical, and physiological characteristics of isolate BA5 (Table 2) were typical properties of species Pseudomonas aeruginosa (Stanier et al. 1966 and Liu 1952). When the morphological, biochemical, and physiological data were submitted in the ABIS online bacterial identification tool (Costin and Ionut 2017), the studied characteristics showed $92 \%$ similarity with $P$. aeruginosa (100\% accuracy). Finally, the systematic affiliation of the isolate was confirmed by16S rRNA gene sequencing. The amplified PCR product of the 16S rRNA gene showed a band approximately at $1.5 \mathrm{~kb}$. A 710-bp $16 \mathrm{~S}$ rDNA partial sequence of isolate BA5 was subjected to compare using BLAST and suggested a close relationship with $P$. aeruginosa (99\% similarity). Phylogenetic analysis indicated that isolate BA5 formed a clade with reference $P$. aeruginosa strain LFII sequences at a bootstrap value of 94\% (Fig. 3). The 16S rDNA sequence was submitted in the NCBI GenBank under the strain name RKA5, and an accession number (MG786551) was received. 
Table 2 Morphological, physiological, and biochemical characteristics of isolate BA5

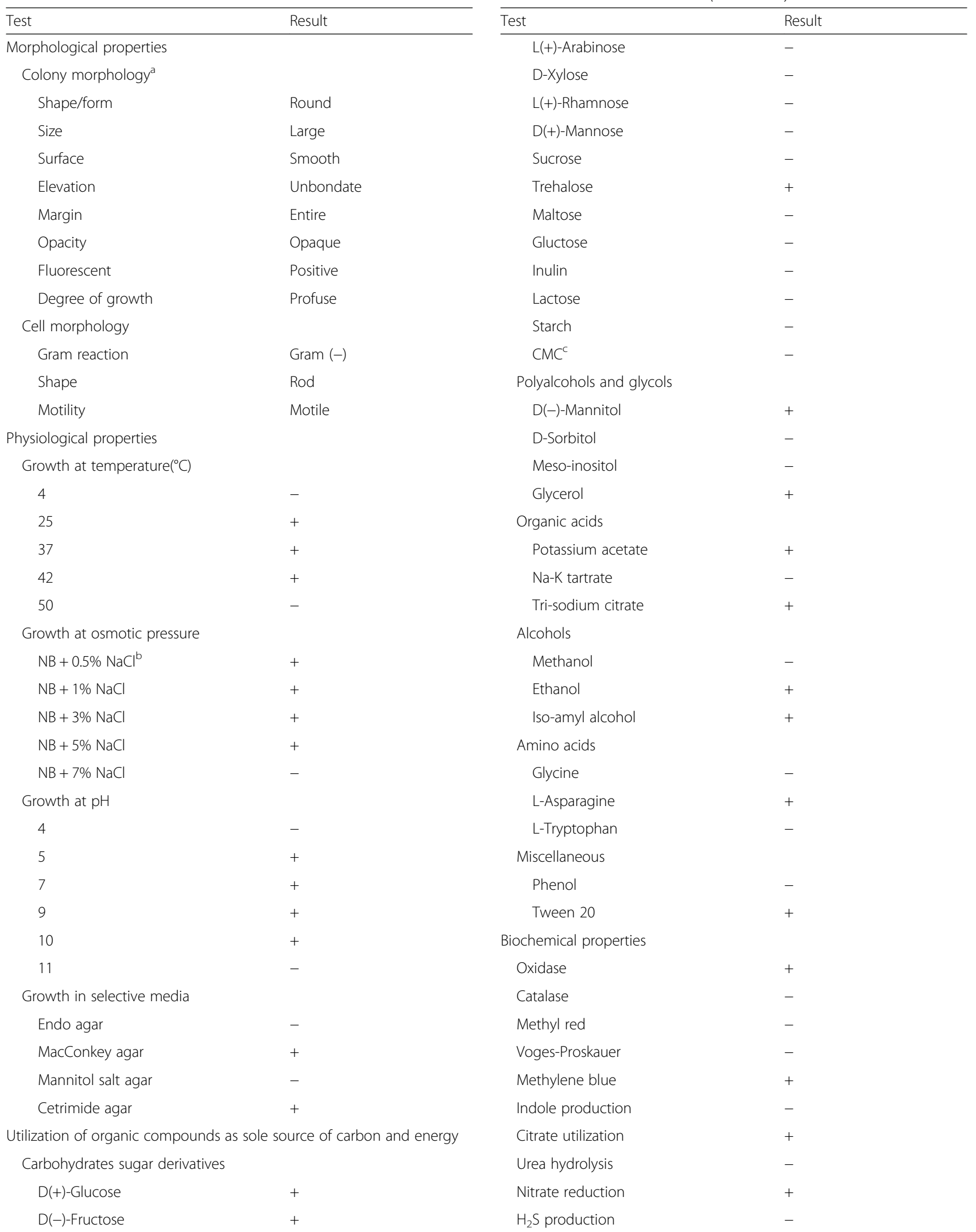

Table 2 Morphological, physiological, and biochemical characteristics of isolate BA5 (Continued) 
Table 2 Morphological, physiological, and biochemical characteristics of isolate BA5 (Continued)

\begin{tabular}{ll}
\hline Test & Result \\
\hline Casein hydrolysis & + \\
Starch hydrolysis & - \\
Fermentation and acid production from & \\
Glucose & + \\
Fructose & - \\
Xylose & + \\
Sucrose & - \\
Lactose & - \\
Starch & - \\
Mannitol & + \\
Sorbitol & - \\
Meso-inositol & - \\
Glycerol & + \\
\hline
\end{tabular}

${ }^{a}$ In King's B agar medium after $24 \mathrm{~h}$ of culture at $30{ }^{\circ} \mathrm{C}$. ${ }^{\mathrm{b}} \mathrm{NB}$ nutrient broth.

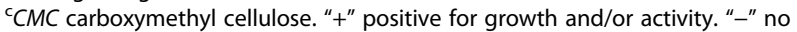
growth or activity

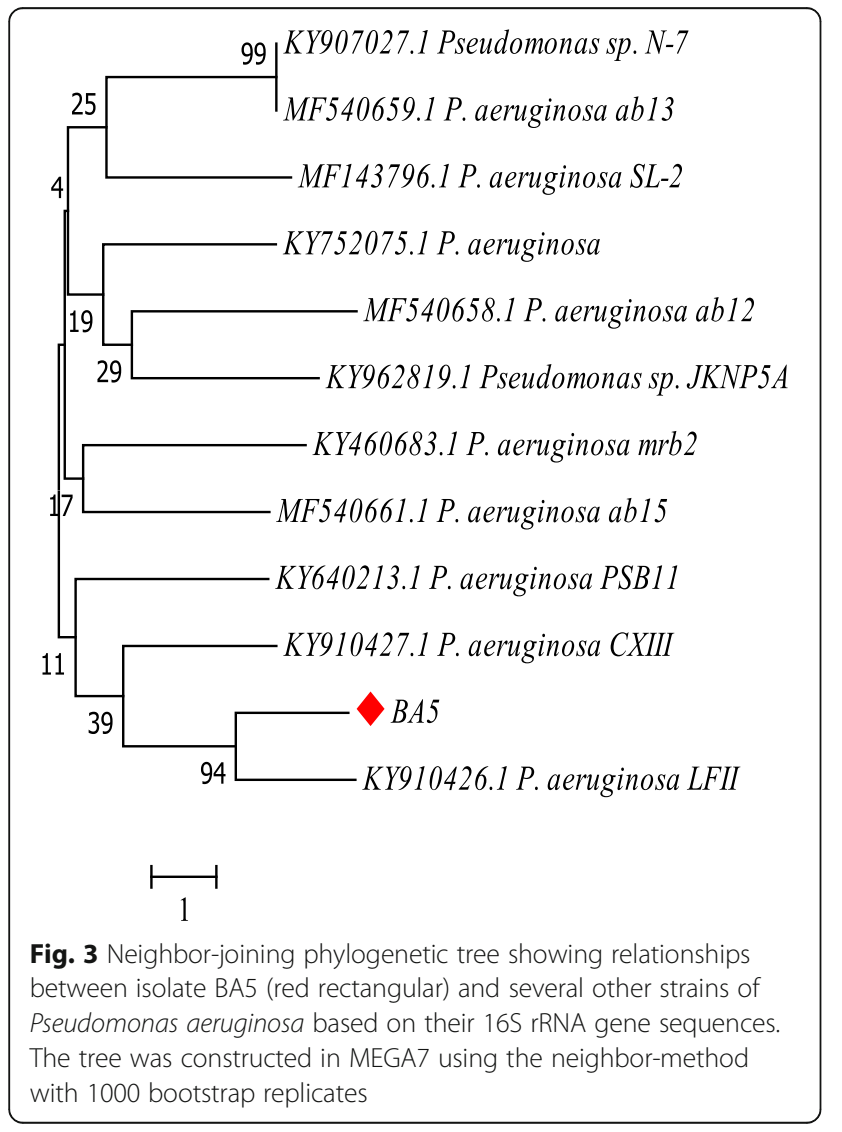

\section{Conclusion}

An attempt was made to isolate rhizobacteria with strong antagonistic activity against the cucumber wilt pathogen Foc. The isolate BA5 was a prominent antagonist against the pathogen and was able to produce various antagonistic compounds, including siderophores and VOCs, as well as it showed plant growth promotion potentials in vitro. The findings suggest that the selected isolate has the potential to be used as a biocontrol agent in the management of Fusarium wilt in cucumber. Nevertheless, field trial is needed to determine the disease suppression efficiency of the isolate in the natural soil environment.

\begin{abstract}
Abbreviations
CFCF: Cell-free culture filtrate; CLP: Cyclic lipopeptide; Foc: Fusarium oxysporum f. sp. cucumerinum; HCN: Hydrocyanic acid; IAA: Indoe-3-acetic acid; KBB: King's B broth; NB: Nutrient broth; PDA: Potato dextrose agar; PDB: Potato dextrose broth; PKV agar: Pikovskaya's agar; TSA: Tryptone soya agar; TSB: Tryptone soya broth; TYEB: Tryptone yeast extract broth; VOCs: Volatile compound(s)
\end{abstract}

\section{Acknowledgements}

The authors wish to thank Associate Professor Dr. Mohammad Minnatul KARIM for providing the standard microorganisms and the Department of Biotechnology and Genetic Engineering, Islamic University, Kushtia, Bangladesh, for providing research facilities. We would also like to thank the anonymous reviewers for their insightful comments in revising the manuscript.

\section{Funding}

This study was supported by the Special Research Allocations for Science and Technology from the Bangladesh University Grant Commission (UGC; Grant No. 4829) and the Islamic University, Kushtia, Bangladesh.

\section{Availability of data and materials}

The datasets used and/or analyzed during the current study are available from the corresponding author on reasonable request.

\section{Authors' contributions}

$\mathrm{MRI}$ and MAI conceived and designed the experiments. MAI performed the experiments. ZN and MAI analyzed the data. MAI and ZN wrote the paper. MRI, MKA, and NAB contributed to the critical review and editing of the manuscript. All authors read and approved the final manuscript.

Ethics approval and consent to participate

Not applicable

\section{Consent for publication}

All authors consent to publish this article in the Egyptian Journal of Biological Pest Control.

\section{Competing interests}

The authors declare that they have no competing interests.

\section{Publisher's Note}

Springer Nature remains neutral with regard to jurisdictional claims in published maps and institutional affiliations.

Received: 1 August 2018 Accepted: 31 October 2018

Published online: 21 November 2018

\section{References}

Ahemad M, Kibret M (2014) Mechanisms and applications of plant growth promoting rhizobacteria: current perspective. J King Saud Univ - Sci 26:1-20. https://doi.org/10.1016/j.jksus.2013.05.001

Ahmed GA (2010) Controlling of Fusarium wilt of cucumber by antagonistic bacteria. J Life Sci 4:16-21 
Al-Tuwaijri MMY (2015) Studies on Fusarium wilt disease of cucumber. J Appl Pharm Sci 5:110-119. https://doi.org/10.7324/JAPS.2015.50216

Bapiri A, Asgharzadesh A, Mujallali H, Khavazi K, Pazira E (2012) Evaluation of zinc solubilization potential by different strains of fluorescent pseudomonads. J Appl Sci Environ Manag 16:295-298

Beneduzi A, Ambrosini A, Passaglia LMP (2012) Plant growth-promoting rhizobacteria (PGPR): their potential as antagonists and biocontrol agents. Genet Mol Biol 35:1044-1051. https://doi.org/10.1590/S1415-47572012000600020

Benson HJ (2002) Microbiological applications: laboratory manual in general microbiology, 8th edn. McGraw Hill, New York

Bric JM, Bostock RM, Silverstonet SE (1991) Rapid in situ assay for indoleacetic acid production by bacteria immobilized on a nitrocellulase membrane. Appl Environ Microbiol 57:535-538

Costin S, Ionut S (2017) ABIS online - Advanced Bacterial Identification Software, an original tool for phenotypic bacterial identification, Regnum Prokaryotae. Available at: www.tgw1916.net, Accessed on 12 Dec 2017

De Bruijn I, Raaijmakers JM (2009) Regulation of cyclic lipopeptide biosynthesis in Pseudomonas fluorescens by the ClpP protease. J Bacteriol 191:1910-1923. https://doi.org/10.1128/JB.01558-08

Deb P, Talukdar SA, Mohsina K, Sarker PK, Sayem SMA (2013) Production and partial characterization of extracellular amylase enzyme from Bacillus amyloliquefaciens P-001. Springerplus 2:154. https://doi.org/10.1186/2193-1801-2-154

Dharni S, Alam M, Kalani K, Khaliq A, Samad A, Srivastava SK, Patra DD (2012) Production, purification, and characterization of antifungal metabolite from Pseudomonas aeruginosa SD12, a new strain obtained from tannery waste polluted soil. J Microbiol Biotechnol 22:674-683

Fatima S, Anjum T (2017) Identification of a potential ISR determinant from Pseudomonas aeruginosa PM12 against Fusarium wilt in tomato. Front Plant Sci 8:1-14. https://doi.org/10.3389/fpls.2017.00848

Fridlender M, Inbar J, Chet I (1993) Biological control of soilborne plant pathogens by a $\beta-1,3$ glucanase-producing Pseudomonas cepacia. Soil Biol Biochem 25:1211-1221. https://doi.org/10.1016/0038-0717(93)90217-Y

Gordon SA, Weber RP (1951) Colorimetric estimation of indoleacetic acid. Plant Physiol 26:192-195

Han J, Shim H, Shin J, Kim KS (2015) Antagonistic activities of Bacillus spp. strains isolated from tidal flat sediment towards anthracnose pathogens Colletotrichum acutatum and C. gloeosporioides in South Korea. Plant Pathol J 31:165-175

He F (2011) E. coli genomic DNA extraction. Bio-Protocol Bio101:e97. https://doi. org/10.21769/BioProtoc.97

Hu W, Gao Q, Hamada MS, Dawood DH, Zheng J, Chen Y, Ma Z (2014) Potential of Pseudomonas chlororaphis subsp. aurantiaca strain Pcho10 as a biocontrol agent against Fusarium graminearum. Phytopathology 104:1289-1297. https://doi.org/10.1094/PHYTO-02-14-0049-R

Islam MR, Jeong YT, Lee YS, Song CH (2012) Isolation and identification of antifungal compounds from Bacillus subtilis C9 inhibiting the growth of plant pathogenic fungi. Micobiology 40:59-65

Islam MT, Deora A, Hashidoko Y, Rahman A, Ito T, Tahara S (2007) Isolation and identification of potential phosphate solubilizing bacteria from the rhizoplane of Oryza sativa L. cv. BR29 of Bangladesh. Zeitschrift fur Naturforsch - Sect C J Biosci 62:103-110

Ji SH, Gururani MA, Chun SC (2014) Isolation and characterization of plant growth promoting endophytic diazotrophic bacteria from Korean rice cultivars. Microbiol Res 169:83-98. https://doi.org/10.1016/j.micres.2013.06.003

Ji SN, Paul NC, Deng JX, Kim YS, Yun B, Yu SH (2013) Biocontrol activity of Bacillus amyloliquefaciens CNU114001 against fungal plant diseases. Mycobiology 41: 234-242

Kandel SL, Firrincieli A, Joubert PM, Okubara PA, Leston ND, McGeorge KM, Mugnozza GS, Harfouche A, Kim SH, Doty SL (2017) An in vitro study of biocontrol and plant growth promotion potential of salicaceae endophytes. Front Microbiol 8:386. https://doi.org/10.3389/fmicb.2017.00386

Kasana RC, Salwan R, Dhar H, Dutt S, Gulati A (2008) A rapid and easy method for the detection of microbial cellulases on agar plates using Gram's iodine. Curr Microbiol 57:503-507. https://doi.org/10.1007/s00284-008-9276-8

Koser SA (1923) Utilization of the salts of organic acids by the colon-aerogenes group. J Bacteriol 8:493-520

Kumar NR, Arasu VT, Gunasekaran P (2002) Genotyping of antifungal compounds producing plant growth-promoting rhizobacteria, Pseudomonas fluorescens. Curr Sci 82:1463-1466

Kumar P, Dubey RC, Maheshwari DK (2012) Bacillus strains isolated from rhizosphere showed plant growth promoting and antagonistic activity against phytopathogens. Microbiol Res 167:493-499. https://doi.org/10.1016/ j.micres.2012.05.002

Kumar RS, Ayyandurai N, Pandiaraja P, Reddy AV, Venkateswarlu Y, Prakash O, Sakthivel N (2005) Characterization of antifungal metabolite produced by a new strain Pseudomonas aeruginosa PUPa3 that exhibits broad-spectrum antifungal activity and biofertilizing traits. J Appl Microbiol 98:145-154. https://doi.org/10.1111/j.1365-2672.2004.02435.x

Kumar S, Stecher G, Tamura K (2016) MEGA7: molecular evolutionary genetics analysis version 7.0 for bigger datasets. Mol Biol Evol 33:1870-1874

Lee T, Park D, Kim K, Lim SM, Yu NH, Kim S, Kim HY, Jung KS, Jang JY, Park JC, Ham H, Lee S, Hong SK, Kim JC (2017) Characterization of Bacillus amyloliquefaciens DA12 showing potent antifungal activity against mycotoxigenic Fusarium species. Plant Pathol J 33:499-507. https://doi.org/10.5423/PPJ.FT.06.2017.0126

Li Q, Jiang Y, Ning P, Zheng L, Huang J, Li G, Jiang D, Hsiang T (2011) Suppression of Magnaporthe oryzae by culture filtrates of Streptomyces globisporus JK-1. Biol Control 58:139-148. https://doi.org/10.1016/j.biocontrol. 2011.04 .013

Liu P (1952) Utilization of carbohydrates by Pseudomonas aeruginosa. J Bacteriol 64(541):773-781

Lopez-Berges MS, Capilla J, Turra D, Schafferer L, Matthijs S, Jochl C, Cornelis P, Guarro J, Haas H, Di Pietro A (2012) HapX-mediated iron homeostasis is essential for rhizosphere competence and virulence of the soilborne pathogen Fusarium oxysporum. Plant Cell 24:3805-3822. https://doi.org/10. 1105/tpc.112.098624

Lu D, Ma Z, Xu X, Yu X (2016) Isolation and identification of biocontrol agent Streptomyces rimosus M527 against Fusarium oxysporum f. sp. cucumerinum. J Basic Microbiol 56:929-933. https://doi.org/10.1002/jobm.201500666

Mannaa M, Oh JY, Kim KD (2017) Biocontrol activity of volatile-producing Bacillus megaterium and Pseudomonas protegens against Aspergillus flavus and aflatoxin production on stored rice grains. Micobiology 45:213-219

Mehnaz S, Saleem RSZ, Yameen B, Pianet I, Schnakenburg G, Pietraszkiewicz H, Valeriote F, Josten M, Sahl HG, Franzblau SG, Harald G (2013) Lahorenoic acids $A-C$, ortho-dialkyl-substituted aromatic acids from the biocontrol strain Pseudomonas aurantiaca PB-St2. J Nat Prod 76:135-141. https://doi.org/10. 1021/np3005166

Michelsen CF, Watrous J, Glaring MA, Kersten R, Koyama N, Dorrestein PC (2015) Nonribosomal peptides, key biocontrol components for Pseudomonas fluorescens In5, isolated from a Greenlandic suppressive soil. MBio 6:e00079-e00015. https:// doi.org/10.1128/mBio.00079-15

Paul D, Sinha SN (2017) Isolation and characterization of phosphate solubilizing bacterium Pseudomonas aeruginosa KUPSB12 with antibacterial potential from river Ganga, India. Ann Agrar Sci 15:130-136. https://doi.org/10.1016/j. aasci.2016.10.001

Priyanka AT, Kotasthane AS, Kosharia A, Kushwah R, Zaidi NW, Singh US (2017) Crop specific plant growth promoting effects of ACCd enzyme and siderophore producing and cynogenic fluorescent Pseudomonas. 3 Biotech 7(1):27. https://doi.org/10.1007/s13205-017-0602-3

Raaijmakers JM, Paulitz TC, Steinberg C, Alabouvette C, Moënne-Loccoz Y (2009) The rhizosphere: a playground and battlefield for soilborne pathogens and beneficial microorganisms. Plant Soil 321:341-361. https://doi.org/10.1007/ s11104-008-9568-6

Ramette A, Frapolli M, Défago G, Moënne-Loccoz Y (2003) Phylogeny of HCN synthase-encoding hcnBC genes in biocontrol fluorescent pseudomonads and its relationship with host plant species and HCN synthesis ability. Mol PlantMicrobe Interact 16:525-535. https://doi.org/10.1094/MPMI.2003.16.6.525

Raza W, Ling N, Liu D, Wei Z, Huang Q, Shen Q (2016) Volatile organic compounds produced by Pseudomonas fluorescens WR-1 restrict the growth and virulence traits of Ralstonia solanacearum. Microbiol Res 192:103-113. https://doi.org/10.1016/j.micres.2016.05.014

Saitou N, Nei M (1987) The neighbor-joining method: a new method for reconstructing phylogenetic trees. Mol Biol Evol 4:406-425

Solanki MK, Singh RK, Srivastava S, Kumar S, Kashyap PL, Srivastava AK, Arora DK (2014) Isolation and characterization of siderophore producing antagonistic rhizobacteria against Rhizoctonia solani. J Basic Microbiol 54:585-596. https:// doi.org/10.1002/jobm.201200564

Solans M, Scervino JM, Messuti MI, Vobis G, Wall LG (2016) Potential biocontrol actinobacteria: rhizospheric isolates from the argentine pampas lowlands legumes. J Basic Microbiol 56:1-10. https://doi.org/10.1002/jobm.201600323

Stanier RY, Palleroni NJ, Doudoroff M (1966) The aerobic pseudomonads: a taxonomic study. J Gen Microbiol 43:159-271. https://doi.org/10.1099/ 00221287-43-2-159 
Sulochana MB, Jayachandra SY, Kumar SKA, Dayanand A (2014) Antifungal attributes of siderophore produced by the Pseudomonas aeruginosa JAS-25. J Basic Microbiol 54:418-424. https://doi.org/10.1002/jobm.201200770 Tian F, Ding Y, Zhu H, Yao L, Du B (2009) Genetic diversity of siderophoreproducing bacteria of tobacco rhizosphere. Brazilian J Microbiol 40:276-284

Trivedi P, Pandey A, Palni LMS (2008) In vitro evaluation of antagonistic properties of Pseudomonas corrugata. Microbiol Res 163:329-336. https://doi.org/10. 1016/j.micres.2006.06.007

Wu DQ, Ye J, Ou HY, Wei X, Huang X, He YW, Xu Y (2011) Genomic analysis and temperature-dependent transcriptome profiles of the rhizosphere originating strain Pseudomonas aeruginosa M18. BMC Genomics 12:1-17. https://doi.org/ 10.1186/1471-2164-12-438

Yang Q-Y, Jia K, Geng W-Y, Guo R-J, Li S-D (2014) Management of cucumber wilt disease by B. subtilis B006 through suppression of F. oxysporum in rhizosphere. Plant Pathol J 13:160-166. https://doi.org/10.3923/ppj.2014.160.166

Yeole RD, Dave BP, Dube HC (2001) Siderophore production by fluorescent pseudomonads colonizing roots of certain crop plants. Indian J Exp Biol 39: 464-468

Yu SM, Lee YH (2015) Genes involved in nutrient competition by Pseudomonas putida JBC17 to suppress green mold in postharvest satsuma mandarin. J Basic Microbiol 55:898-906. https://doi.org/10.1002/jobm.201400792

Zhang Q, Ji Y, Xiao Q, Chng S, Tong Y, Chen X, Liu F (2016) Role of Vfr in the regulation of antifungal compound production by Pseudomonas fluorescens FD6. Microbiol Res 188-189:106-112. https://doi.org/10.1016/j.micres.2016.04.013

Zhou T, Chen D, Li C, Sun Q, Li L, Liu F, Shen Q, Shen B (2012) Isolation and characterization of Pseudomonas brassicacearum $\mathrm{J} 12$ as an antagonist against Ralstonia solanacearum and identification of its antimicrobial components. Microbiol Res 167:388-394. https://doi.org/10.1016/j.micres.2012.01.003

\section{Submit your manuscript to a SpringerOpen ${ }^{\circ}$ journal and benefit from:}

- Convenient online submission

- Rigorous peer review

- Open access: articles freely available online

- High visibility within the field

- Retaining the copyright to your article

Submit your next manuscript at $\boldsymbol{\nabla}$ springeropen.com 